\title{
Enhanced Freshwater Production Using Finned- Plate Air Gap Membrane Distillation (AGMD)
}

\author{
Mohammad Jabed Perves Bappy ${ }^{1}$, Rubina Bahar $^{1,}{ }^{,}$, Shaliza Ibrahim $^{2}$ and Tasnim Firdaus \\ Ariff $^{1}$ \\ ${ }^{1}$ Department of Manufacturing and Materials Engineering, International Islamic University Malaysia, \\ 50728 Kuala Lumpur, Malaysia \\ ${ }^{2}$ Department of Civil Engineering, University of Malaya, 50603 Kuala Lumpur, Malaysia
}

\begin{abstract}
Air Gap membrane distillation (AGMD), a special type of energy efficient membrane distillation process, is a technology for producing freshwater from waste water. Having some benefits over other traditional processes, this method has been able to draw attention of researchers working in the field of freshwater production technologies. In this study, a basic AGMD system with flat coolant plate has been modified using a specially designed channelled coolant plate of portable size to observe its effect over the production rate and performance of the system. Attempt has been made to increase the amount of distillate flux by using the "fin effect" of the channelled coolant plate. A finned plate have been used instead of a flat coolant plate and experiments were conducted to compare the effect. Coolant temperature and feed temperature of the system have been varied from $10^{\circ} \mathrm{C}$ to $25^{\circ} \mathrm{C}$ and $40^{\circ} \mathrm{C}$ to $70^{\circ} \mathrm{C}$ respectively. Comparing the data, around $50 \%$ to $58 \%$ distillate enhancement has been observed for channelled coolant plate. Also, it was seen that the enhancement was higher for higher feed temperatures and coolant temperatures. With these findings, a better performing AGMD module has been introduced to mitigate the scarcity of freshwater.
\end{abstract}

\section{Introduction}

Membrane distillation (MD) is becoming one of the most popular technique of wastewater treatment in recent years which combines the benefits of thermal and membrane separation processes [1]. The process contains a hot aqueous solution or wastewater side which purifies itself by being separated through a very thin microporous hydrophobic membrane toward a cooler side with lower temperature. The hydrophobic nature of the membrane prevents penetration of the aqueous solution into the pores, resulting in a vapour-liquid interface at each pore entrance. The driving force in the MD process is the vapour pressure difference induced by the temperature difference across the hydrophobic membrane [2] . MD is somewhat a recent technique with its energy efficient nature and cost effectiveness

* Corresponding author: rbahar@iium.edu.my 
which allow it to be installed anywhere in the world with minimum capital compared to other methods available in the market [3].

The common available methods of treating wastewater includes thermal distillation and reverse osmosis (RO). Thermal distillation requires special infrastructure to install and RO needs very high pressure to overcome the osmotic pressure. Also the feasibility of thermal distillation is decreasing for its high energy consumption as energy saving is becoming a big issue around the world. Reverse Osmosis in still a popular one but have limitations above $50^{\circ} \mathrm{C}$ where the membrane quality deteriorates significantly which degrades the performance of the system [4]. Membrane distillation fairly overcomes the limitation of thermal distillation and reverse osmosis. The requirement of very low grade energy and high customizability give it the added advantages over those processes [5].

The work aims to improve the overall production from a small scale wastewater treatment system by implementing channelled coolant plates instead of the traditionally used flat plates. The coolant plate is used in a special type of water purification system which is called Air Gap Membrane Distillation (AGMD) [5]. It is a type of MD process where the vapour from the waste/saline water travels through the hydrophobic membrane pores and gets condensed on the cooler side on a condensing (coolant) plate [6]. If the coolant plate can be designed and manufactured with channels, it would impose a "fin"effect on the coolant side which subsequently would accelerate condensation and thus make more room for more vapour to come in. As AGMD units are compact and portable, and does not need high pressure/temperature [6-9], it seems to be a promising technology for water supply in the arid and remote areas with water scarcity. Improvement of this system by implementing channelled coolant plates will aid in the productivity and help to maintain future demand.

\section{Experimental procedure and setup}

\subsection{Design}

The 3-D design of the AGMD module has been done using Solidworks 2013 CAD software package. Dimensions have been chosen to maintain the portability of the system. The complete module have five basic parts; 1) Hot solution Chamber, 2) Membrane ramp, 3) Air gap frame, 4) Fined coolant plate and 5) Cold solution chamber. The dimension of the two chambers, hot and cold, was selected as $162.40 \times 106.60 \mathrm{~mm}$. A detailed drawing of the two symmetric chambers is shown in Fig. 1. The inlet $15 \mathrm{~mm}$ diameter pipe of the feed chamber was inclined at $60^{\circ}$ angle with the base of the chambers. The angle was given so that the stream of circulating hot water can hit the membrane directly thus reducing polarization of temperature and concentration on the evaporating surface. Exit pipe diameter was $15 \mathrm{~mm}$ too with straight $90^{\circ}$ angle with the chamber. 
a)

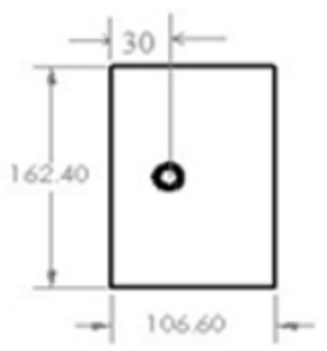

b)

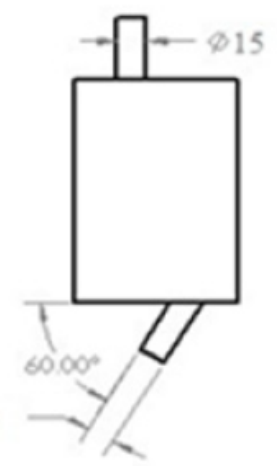

d)

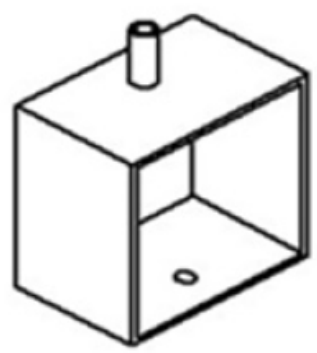

c)

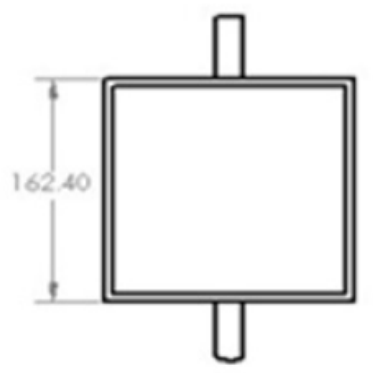

Fig. 1. Design of the hot and cold solution chamber a) top view, b) front view, c) side view and d) isometric view.

The study mainly focussed on implementing the finned coolant plate which was designed very carefully. 60 fins were put on the $165.33 \mathrm{~mm} * 165.33 \mathrm{~mm}$ sized plate. Each fin's dimension is $30 \mathrm{~mm} * 5 \mathrm{~mm}$. The detail spacing of the fins are shown in Fig. 2 where front, top, side \& isometric view of the finned plate is mentioned.

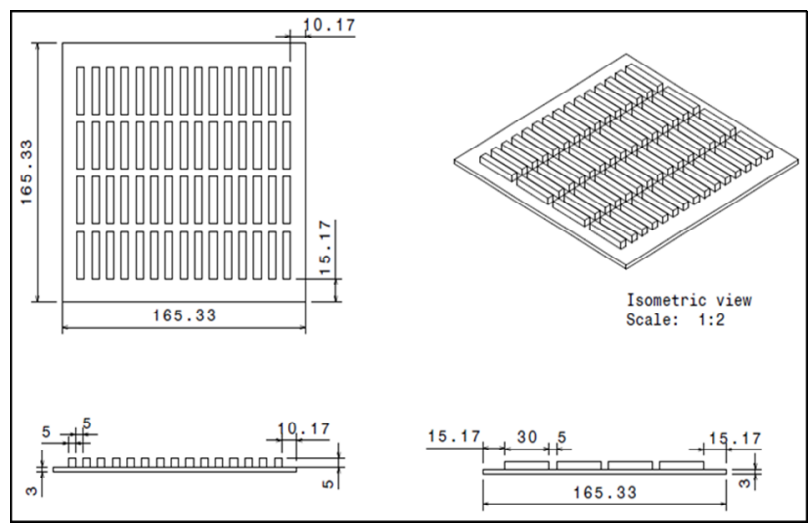

Fig .2. Design of the channeled coolant plate (front, top, side and isometric view).

The membrane ramp dimension have been shown in Fig. 3 where it can be seen that the rectangular plates dimension is $202 * 202 \mathrm{~mm}$. Membrane will sit on the ramp in the middle. The inside hollow circle's diameter is $134 \mathrm{~mm}$. The thickness of the ramp is $5 \mathrm{~mm}$. Four holes on the four corners of the ramp have been made to screw it up with the module with a diameter of $7 \mathrm{~mm}$. Air gap frame is a rectangular frame which will provide the air gap for AGMD system. 
a)

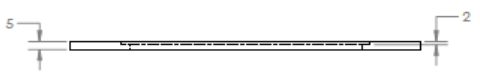

b)

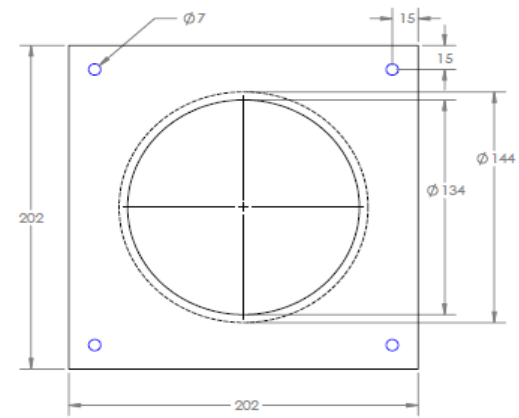

c)
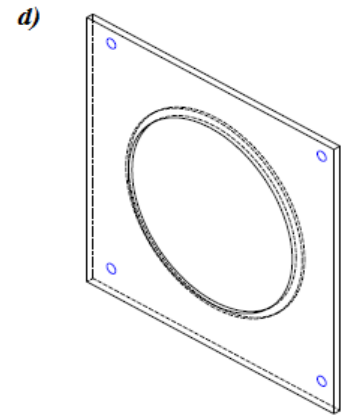

Fig. 3. Design of the membrane ramp of AGMD module a) top view, b) front view, c) right side view and $\mathrm{d}$ ) isometric view.

The air gap was considered $5 \mathrm{~mm}$. And the overall design parameters are summarized in Table 1.

Table 1. Design parameters of the AGMD module (Rect.=Rectangular).

\begin{tabular}{|c|c|c|c|c|c|c|c|}
\hline \multicolumn{2}{|c|}{$\begin{array}{c}\text { Hot \& cold } \\
\text { Chambers }\end{array}$} & \multicolumn{2}{c|}{ Membrane Ramp } & \multicolumn{2}{c|}{ Air gap frame } & \multicolumn{2}{c|}{ Finned Coolant plate } \\
\hline Shape & $\begin{array}{c}\text { Rect. } \\
\text { box }\end{array}$ & Shape & $\begin{array}{c}\text { Rect. } \\
\text { plate } \\
(\mathrm{mm})\end{array}$ & Shape & $\begin{array}{c}\text { Rect. } \\
\text { hollow } \\
\text { frame } \\
(\mathrm{mm})\end{array}$ & Shape & $\begin{array}{c}\text { Rect. } \\
\text { finned } \\
\text { plate }\end{array}$ \\
\hline Height & $\begin{array}{c}162.40 \\
\mathrm{~mm}\end{array}$ & Height & 202 & Height & 165.33 & Height & $165.33 \mathrm{~mm}$ \\
\hline Width & $\begin{array}{c}162.60 \\
\mathrm{~mm}\end{array}$ & Width & 202 & Width & 165.33 & Width & $\begin{array}{c}165.33 \\
\mathrm{~mm}\end{array}$ \\
\hline Length & $\begin{array}{c}106.60 \\
\mathrm{~mm}\end{array}$ & $\begin{array}{c}\text { Hollow } \\
\text { circle dia }\end{array}$ & 134 & $\begin{array}{c}\text { Frame } \\
\text { thickness }\end{array}$ & 5 & $\begin{array}{c}\text { Fin } \\
\text { height }\end{array}$ & $30 \mathrm{~mm}$ \\
\hline Inlet Dia & $15 \mathrm{~mm}$ & $\begin{array}{c}\text { Ramp area } \\
\text { thickness }\end{array}$ & 5 & $\begin{array}{c}\text { Material } \\
\text { thickness }\end{array}$ & 5 & Fin width & $5 \mathrm{~mm}$ \\
\hline $\begin{array}{c}\text { Outlet } \\
\text { Dia }\end{array}$ & $15 \mathrm{~mm}$ & $\begin{array}{c}\text { Screw hole } \\
\text { Dia }\end{array}$ & 7 & -- & -- & $\begin{array}{c}\text { Number } \\
\text { of fins }\end{array}$ & 60 \\
\hline $\begin{array}{c}\text { Inlet } \\
\text { angle }\end{array}$ & $60^{\circ}$ & $\begin{array}{c}\text { Material } \\
\text { Thickness }\end{array}$ & 5 & -- & -- & $\begin{array}{c}\text { Material } \\
\text { thickness }\end{array}$ & $3 \mathrm{~mm}$ \\
\hline
\end{tabular}

\subsection{Materials}

The material selection for fin included an intensive literature study to understand the suitability. A material with cost effectiveness, easy machinability and thermal effiectiveness was to be selected. Considering all the factors, aluminium was chosen to be used with significantly high thermal conductivity compared to other available materials [10]. PTFE hydrophobic membrane of $0.50 \mu \mathrm{m}$ pore size and $150 \mu \mathrm{m}$ thickness with $85 \%$ porosity was used from Fluoropore membrane series supplied by Merck Millipore. 
Material for the other parts of the module was made mainly by grade ' $A$ ' polycarbonate sheets. Thickness of the sheet was $5 \mathrm{~mm}$. Dichloromethane was used to join the polycarbonate sheet to make the box sized chamber as it provide a weld like joint making a chemical bonding with the polycarbonate sheets which is very effective for high temperature operation. High quality silicon glue was used to make the chambers airtight. The overall 3-D design of the module can be seen in Fig. 4. The circulation pipes were made from reinforced PVC. Steel rings and water regulators were used to control the bending of the PVC pipe and water flow inside the water circulating pipe.
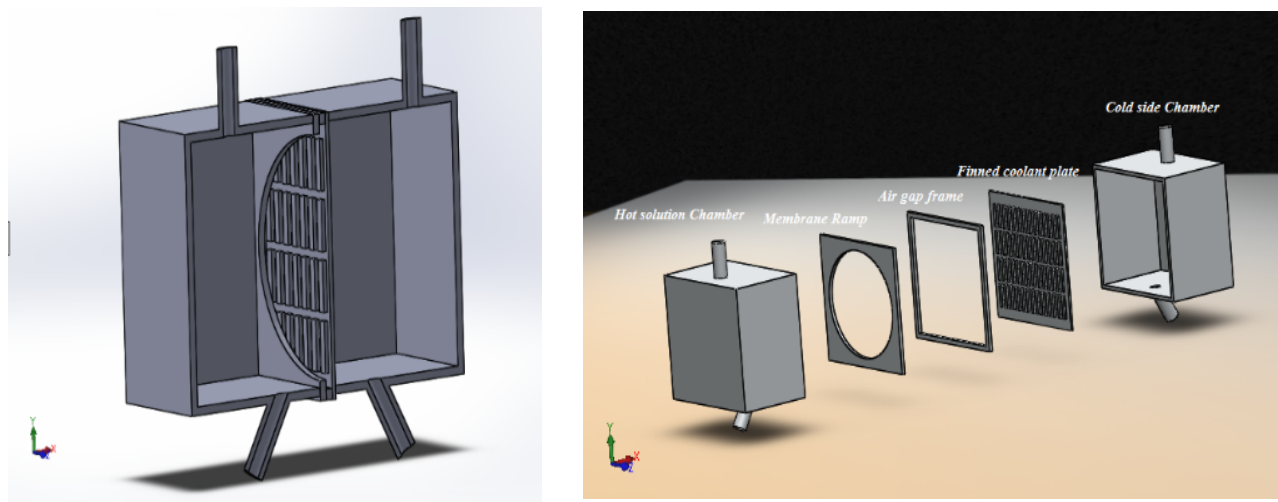

Fig. 4. The 3D design of the AGMD module using Solidworks 2013 software package.

\subsection{Construction and experimental setup}

For the construction of the whole AGMD setup, Polycarbonate sheets were cut very precisely with $\mathrm{CNC}$ milling machine according to the dimension from the design using Gcodes. The cut pieces were joined to build the box using high quality epoxy glue and dichloromethane chemical additive. $2.5 \mathrm{~mm}$ screws have been used to combine all five parts into a compact chamber. The whole box was put on a steel frame base and all the PVC pipelines was joined later. The edges of the pipelines and chambers have been sealed to make it air and water tight using silicon glue.

The experimental setup is shown in Fig. 5 indicating the major parts including the schematic, overall experimental setup and the membrane holding module. Two sets of LAUDA Alpha RA8 Heating and cooling thermostats recirculated the flow of hot feed and coolant. The feed used was tap water mixed with food colour. The food colour was mixed to observe any immediate leakage in membrane. The distillate colour should be totally transparent and this was the major criteria during experiments. The temperature difference between hot and cold side drives the vapour to pass the membrane and travel through the air gap to condense on the coolant plate. As the PTFE hydrophobic membrane only allows the vapour to pass through the membrane, it completely separates any impurities on that water. The vapour get condensed on the plate and can be collected as distillate from the below of the chamber inside a graduated distillate collection beaker. 


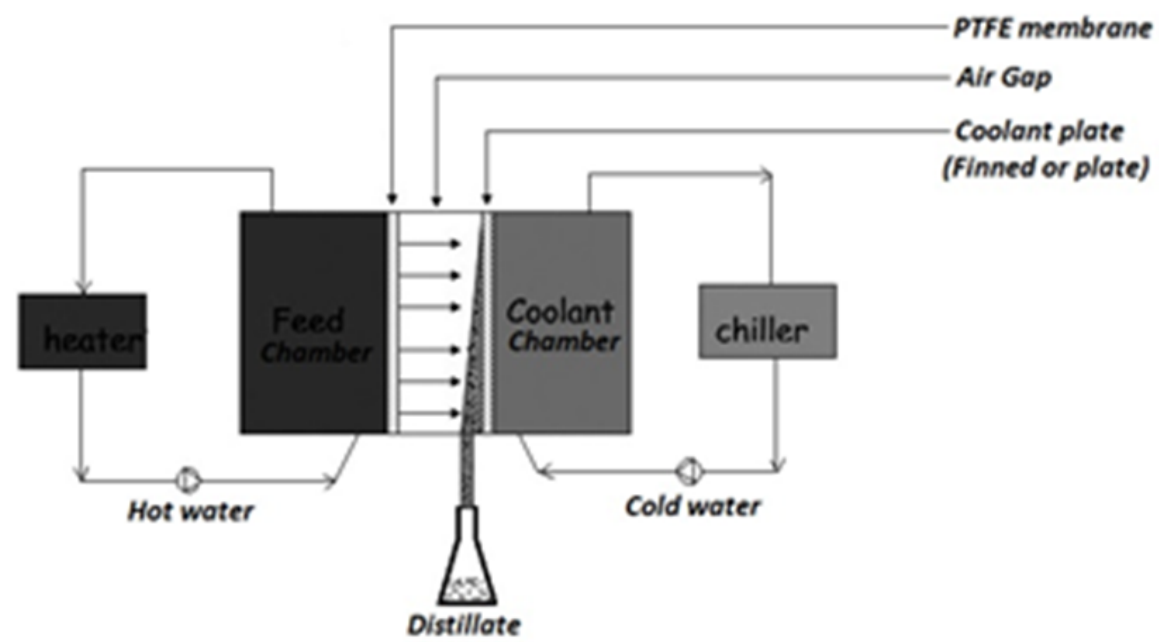

Fig. 5. Experimental setup of the AGMD module (a) Schematic diagram (b) Overall setup (c) Membrane Module

Data were taken varying the feed and coolant temperatures. Coolant temperature was varied from $10^{\circ} \mathrm{C}$ to $25^{\circ} \mathrm{C}$ with $5^{\circ} \mathrm{C}$ minor. On the other hand feed temperatures was varied from $40^{\circ} \mathrm{C}$ to $70^{\circ} \mathrm{C}$ with the same minor. Distillate was collected in every 10 minutes for every single data using a scaled measuring beaker. The flowrate was further lowered from the supply source( LAUDA recirculator) using a flowrate valve and was kept constant throughout the experiments. Temperatures have been measured with $0.1 \mathrm{~mm}$ thermocouple temperature probes with an accuracy of $0.5^{\circ} \mathrm{C}$.

\section{Results and discussion}

In the study, the amount of freshwater production was observed after using channelled coolant plate instead of a flat plate. The evaporation process on the surface of the membrane got tweaked and increased largely because of the increased condensation heat transfer surface of the fin.

The vapour coming out of the membrane pore found a bigger area to condense, thus in a way, the partial pressure difference was manipulated. The feed temperature is varied from $40^{\circ} \mathrm{C}$ to $70^{\circ} \mathrm{C}$ on this experiment where cold side temperature was varied from $10^{\circ} \mathrm{C}$ to $25^{\circ} \mathrm{C}$. From Fig. 6 it can be observed that a significant enhancement of the distillate flux was found in channelled plat compared to flat plate for different coolant temperatures. It was also observed that, with higher feed temperature, the enhancement in production with finned plate was also increasing. Fig. 7 shows the percentile increase in freshwater production using the channelled coolant plate for various coolant temperatures. The effect of fins in producing freshwater was more dominant for increased coolant temperature as well. 
a)

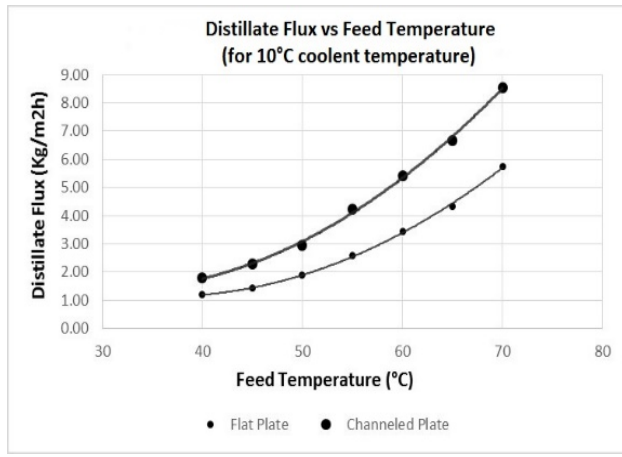

c)

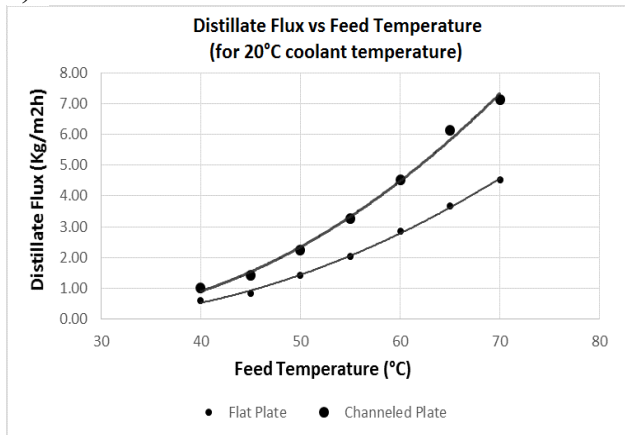

b)

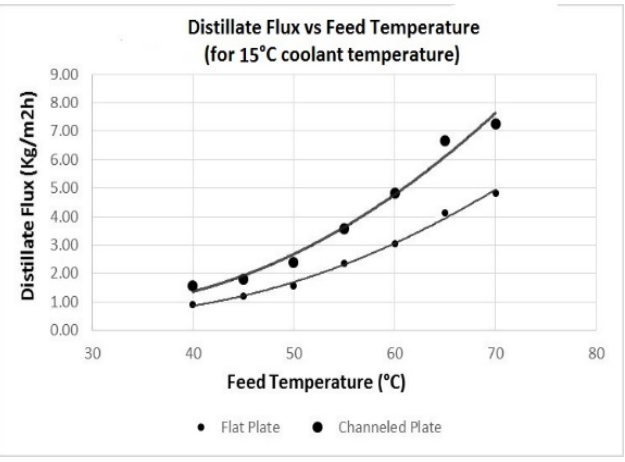

d)

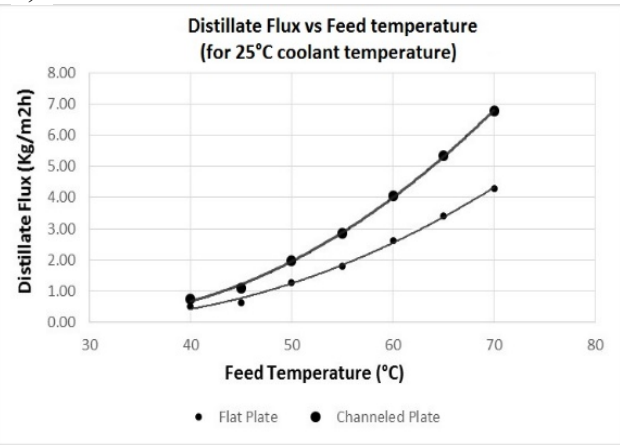

Fig. 6. Distillate Flux vs Feed temperature graph at a) $10^{\circ} \mathrm{C}$ coolant side temperature, b) $15^{\circ} \mathrm{C}$ coolant side temperature, c) $20^{\circ} \mathrm{C}$ coolant side temperature and d) $25^{\circ} \mathrm{C}$ coolant side temperature.

\section{Performance increase (Flat to channelled)}

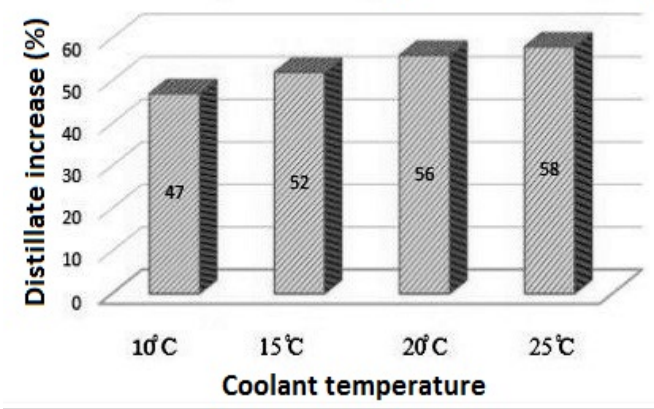

Fig. 7. Performance increase of the system from flat to channelled collant plate at various coolant temperatures. 


\section{Conclusion}

Finned/channelled coolant plate has been able to increase the freshwater production rate significantly for a lab scale AGMD unit. After imposing 60 fins, the increased distillate production of $47 \%, 52 \%, 56 \%$ and $58 \%$ have been achieved respectively at $10^{\circ} \mathrm{C}, 15^{\circ} \mathrm{C}$, $20^{\circ} \mathrm{C}$ and $25^{\circ} \mathrm{C}$ coolant side temperatures. This increment has been influenced by the trend in increasing feed and coolant temperatures. The distillate was collected through a sealed path inside a sealed container. However, some entrapment of the distillate droplets has been observed on the top surface of each fin; this condition can be eliminated with a circular fin. The increased performance of the module can supply more amount of fresh water per unit time which will make the system more cost effective and can be made usable in daily basis even in home environment with a compact design. The initial feed water used for this study was coloured tap water. In future, household waste water will be used as the feed after necessary pre-treatment.

The work was jointly supported by Fundamental Research Grant Scheme (FRGS-14-118-0359), IIUM Endowment fund (EDW B14-134-1019) and IIUM-UM joint grant (CG015-2014) by providing necessary financial and technical assistance for this project.

\section{References}

[1] A. Alklaibi and N. Lior, Membrane-distillation desalination: status and potential. Desalination, 171,(2), (2005)

[2] S. Bouguecha, R. Chouikh and M. Dhahbi, Numerical study of the coupled heat and mass transfer in membrane distillation, Desalination, 152(1), (2003).

[3] A. Alkhudhiri, N. Darwish and N. Hilal, Membrane distillation: a comprehensive review, Desalination, 287, (2012).

[4] K.P. Lee, T.C. Arnot and D. Mattia, A review of reverse osmosis membrane materials for desalination-development to date and future potential, J. Membr. Sci., 370(1), (2011).

[5] R. Tian, H. Gao, X.H. Yang, S.Y. Yan and S. Li, A new enhancement technique on air gap membrane distillation, Desalination, 332(1), (2014).

[6] U. Dehesa-Carrasco, C. Pérez-Rábago and C. Arancibia-Bulnes, Experimental evaluation and modeling of internal temperatures in an air gap membrane distillation unit, Desalination, 326,(2013).

[7] M.I. Ali, E.K. Summers and H.A. Arafat, Effects of membrane properties on water production cost in small scale membrane distillation systems, Desalination, 306, (2012).

[8] A. Alkhudhiri, N. Darwish and N. Hilal, Treatment of saline solutions using air gap membrane distillation: experimental study, Desalination, 323, (2013).

[9] Geng, H., et al., Experimental study of hollow fiber AGMD modules with energy recovery for high saline water desalination. Desalination, 344, (2014).

[10] J.R. Davis and J.R. Davis, Aluminum and aluminum alloys, ASM international, (1993). 